$\mathbb{T}$ periodica polytechnica

Chemical Engineering

$51 / 1(2007) 11+16$

doi: 10.3311/pp.ch.2007-1.03

web: http://www.pp.bme.hu/ch

(c) Periodica Polytechnica 2007

RESEARCH ARTICLE

\section{Retrofit design of an energy integrated distillation system}

\author{
Hajnalka Kencse / József Manczinger / Zsolt Szitkai / Péter Mizsey
}

Received 2006-10-03

\begin{abstract}
This work presents the retrofit design of an industrial $\mathrm{N}, \mathrm{N}$ dimethylformamid (DMF)-water separation system originally consisting of three heat-integrated distillation columns. Our task was to examine how the capacity of the separation system could be increased by $42.8 \%$. If necessary an unused onsite extra distillation column was available for the project. The performance of the existing distillation system and of various increased-capacity structures have been studied using rigorous process simulation. Our study shows that the required capacity increase can be attained by adding the extra distillation column only when replacing the column internals of the original columns and when installing a new structured packing also into the available extra column. Replacing the column internals is expected to result in better controllability, too.
\end{abstract}

\section{Keywords}

energy integration · distillation · dimethylformamide retrofit $\cdot$ simulation

\section{Hajnalka Kencse}

Department of Chemical Engineering, BME, H-1111, Budapest, Múegyetem rakpart 3., Hungary

\section{József Manczinger}

Department of Chemical Engineering, BME, H-1111, Budapest, Múegyetem rakpart 3., Hungary

\section{Zsolt Szitkai}

Department of Chemical Engineering, BME, H-1111, Budapest, Múegyetem rakpart 3., Hungary

\section{Péter Mizsey}

Department of Chemical Engineering, BME, H-1111, Budapest, Múegyetem rakpart 3., Hungary

e-mail: mizsey@mail.bme.hu

\section{Introduction}

$\mathrm{N}, \mathrm{N}$-dimethylformamid (DMF) is a well known solvent of many hydrophobic organic compounds. DMF is also used as crystallization medium in the pharmaceutical industries but the main consumer of DMF is the polymer industry. Production and processing of polyamide and acrylic fibers, films, coatings and wire enamels all require the usage of DMF.

The solvent spinning process that is used for the production of polyamide fibers uses large amounts of DMF. The polymer is dissolved in DMF resulting in a solution that is suitable for extrusion through a spinneret. The extrusion is followed by the precipitation of the polymer fiber with the help of an aqueous bath. In the last step of the technology the DMF is to be recovered from an aqueous solution, so it can be used again as a solvent.

DMF-water mixtures are separated using distillation. Although the DMF and the water constitute an ideal mixture and could be separated in a single distillation column, in the industrial practice usually a two-column heat integrated sequence is used for the separation. The initial approx $40 \mathrm{wt} \%$ DMF containing solution is fed into a vacuum column. The top product of the vacuum column is pure water; the bottom product enriched in DMF is fed into the second column that is operated at atmospheric pressure. The bottom product of the atmospheric column is pure DMF, while the top product of the atmospheric column is pure water. The overhead vapour of the atmospheric column provides the heat that is necessary for boiling up the vacuum column. The condenser of the atmospheric column and the reboiler of the vacuum column are replaced hence by a single heat exchanger. This arrangement is called direct distillation sequence with backward heat integration.

Usually large amounts of energy can be saved when using heat-integrated distillation sequences as demonstrated e.g. by Annakou and Mizsey [1] and Rév et al. [10]. Annakou and Mizsey [1] found that heat-integrated sequences are always more economic than the conventional direct or indirect separation sequences. 


\section{General Aim of the Work}

The general aim of this work is to suggest process modifications that enable the capacity increase of an existing DMF-water separation system that is operated at the site of a Hungarian polymer fiber production plant. The performance of the existing energy-integrated distillation system and of various increasedcapacity alternatives are studied using rigorous process simulation. Process modifications are suggested based on the simulations exclusively.

\section{Description of the Existing Separation Process}

Scheme of the DMF recovery system of an existing Hungarian polymer fiber production plant is shown in Fig. 1 The DMF is recovered from 14 tons $/ \mathrm{h} 60 \mathrm{wt} \%$ water containing aqueous solution.

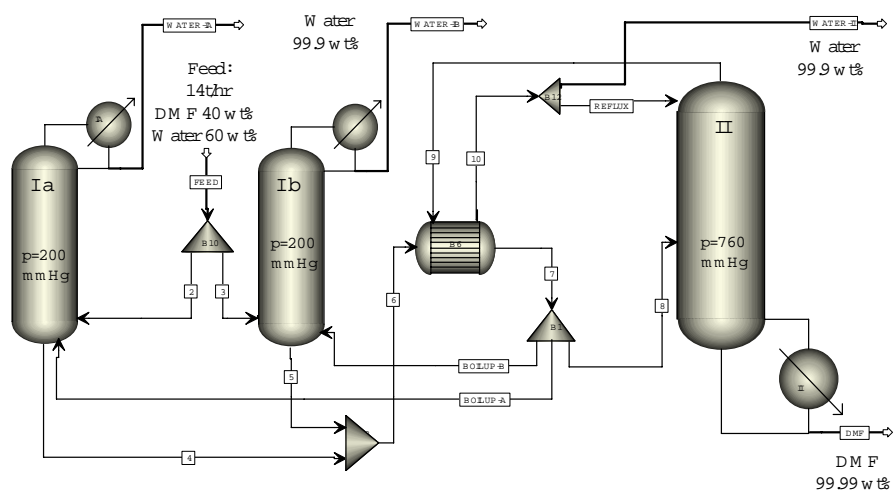

Fig. 1. The original DMF-water separation system with backward heat integration

At this particular plant the crude DMF solution is fed into two parallel connected distillation columns: Ia, Ib that are operated at $200 \mathrm{mmHg}$ vacuum. The column internal of these two columns is an elder type of Sulzer Mellapak structured packing. The vacuum columns produce a $99.9 \mathrm{wt} \%$ water containing distillate and a bottom product that contains approximately $60 \mathrm{wt} \%$ DMF and $40 \mathrm{wt} \%$ water.

The vapour phase bottom products of the vacuum columns are fed into an atmospheric pressure distillation column (column II), that contains trays as column internals. Column II produces a 99.9 wt\% water containing distillate and an extremely pure (99.99 wt\%) DMF in the bottom. The latter is the main product of the separation system. Low water content of the purified DMF is a key factor of the polymer fiber production.

All relevant data of the existing separation system and distillation columns are known, except for the exact type of structured packing that is installed in the vacuum columns.

The columns are heat-integrated; the overhead vapour of the atmospheric column boils up the parallel connected two vacuum columns (Fig. 1). The capacity of the existing separation structure is $14 \mathrm{t} / \mathrm{h}$ that is to be increased now up to $20 \mathrm{t} / \mathrm{h}$.

\section{Simulation of the Existing Separation Process}

Simulation of the existing separation system has been carried out at first. Our study deals with the basic chemical engineering retrofit design of the system, therefore, pumps and other supplementary technological elements are not considered in the simulations. For simplicity, the two parallel connected vacuum columns are simulated as a single distillation column. Structure of the original separation system - as it is simulated - is shown in Fig. 2

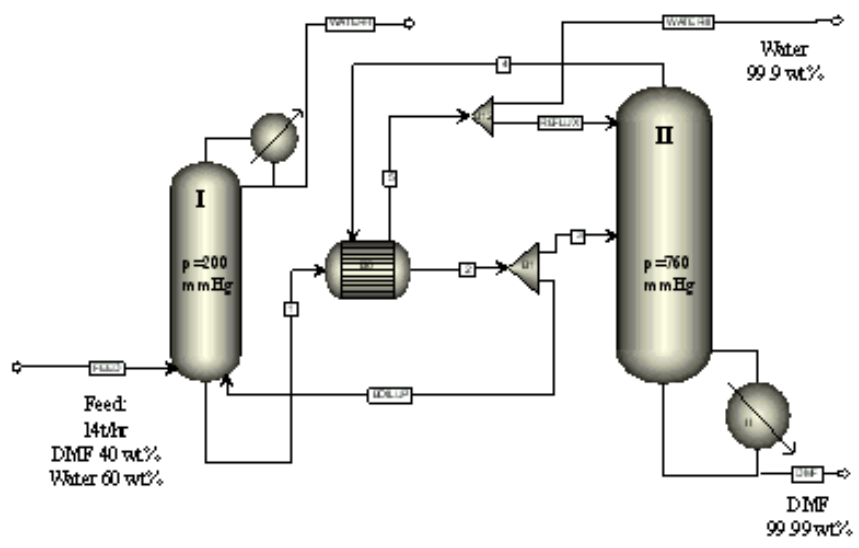

Fig. 2. Simulation of the original DMF-water separation system

Simulation calculations have been carried out using the ChemCad 5.1.3 and the Aspen Plus 12.1 process simulators. In order to avoid numerical difficulties, simulation of the system shown in Fig. 2 has been built up in a stepwise manner:

- First, the two parallel vacuum columns have been simulated (as one column)

- Then the second, atmospheric distillation column has been added

- Finally, the heat-integrated separation system has been simulated.

The UNIQUAC model is used to calculate vapour-liquid equilibrium. Specifications of the columns of the existing separation system are shown in Table 1

Tab. 1. Specifications of the columns of the existing separation system

\begin{tabular}{lcc}
\hline & $\begin{array}{c}\text { Column I } \\
(200 \mathrm{mmHg})\end{array}$ & $\begin{array}{c}\text { Column II } \\
(760 \mathrm{mmHg})\end{array}$ \\
\hline Pressure $(\mathrm{mmHg})$ & 200 & 760 \\
No. of theoretical trays & 16 & 27 \\
Feed stage & 16 & 17 \\
Feed thermal condition & Partially vapourized & Totally vapourized \\
Reflux ratio & 0.57 & 0.86 \\
Column diameter $(\mathrm{mm})$ & Col. la: 1000, Col. lb: 1400 & 2000 \\
\hline
\end{tabular}

As Table 1 shows, the packed vacuum columns have been simulated as if they were trayed columns. Numbers of theoretical trays of the packed columns have been calculated using the packed height of the columns and HETP vs. F factor diagram. 
The Height Equivalent to a Theoretical Plate (HETP) is a key parameter for describing mass-transfer efficiency in structured packing. This is the height of packing required to produce a separation identical in composition to that of an ideal device in which the exiting vapour and liquid are in thermodynamic equilibrium. Column designers use the HETP to calculate the height of packing necessary to achieve a given separation. The HETP depends on the geometry of the packing, the physical properties of the chemical system, and the operating conditions of the column [9].

The HETP-F factor diagram of the assumed type of Sulzer packing (presumably Sulzer Mellapak 250-350, regarding that the present separation system was built in the early eighties) has been used for calculations. Since aqueous mixtures do not wet the packing as well as it is assumed in the Sulzer HETP-F factor diagrams, the value of the theoretical trays obtained this way had to be divided by two. According to Kister [6], separation efficiency of the Sulzer Mellapak packings in case of rectifying aqueous mixtures is half of the efficiency that can be observed in case of organic mixtures.

Simulation calculation of the existing separation process gave back exactly the flow rate and composition data of the columns that could be measured in the plant. From the point of view of heat integration, the most important data are the heat duty and temperature of the condenser of the atmospheric column, and those of the reboiler of the vacuum column. These data are shown in Tables 2 and 3

Tab. 2. Reboiler data of the vacuum columns

\begin{tabular}{ccc} 
& $\begin{array}{c}\text { Bottom temperature } \\
{\left[{ }^{\circ} \mathrm{C}\right]}\end{array}$ & $\begin{array}{c}\text { Reboiler heat duty } \\
{[\mathrm{kW}]}\end{array}$ \\
\hline Column I $(200 \mathrm{mmHg})$ & 70.47 & 4265.03 \\
\hline
\end{tabular}

Tab. 3. Condenser data of the atmospheric column

\begin{tabular}{lcc}
\hline & $\begin{array}{c}\text { Top temperature } \\
{\left[{ }^{\circ} \mathrm{C}\right]}\end{array}$ & $\begin{array}{c}\text { Condenser heat duty } \\
{[\mathrm{kW}]}\end{array}$ \\
\hline Column II $(760 \mathrm{mmHg})$ & 99.63 & -4887.14 \\
\hline
\end{tabular}

As Tables 2 and 3 show, both the temperatures and the heat duties enable heat integration between the two columns. Heat duty values of Table 2 show that the condenser of the atmospheric column provides more heat than it is necessary to boil up the vacuum columns. In reality the difference between the absolute values of the heat duties is the heat loss of the existing system (around 12\%). When simulating the heat-integrated model a trim condenser was used to account for the heat loss.

Usually, the least expensive way of increasing the capacity of existing distillation columns is the replacement of the original column internals with new, high efficiency structured packings. Selection of the packing type requires column vapour load data. Simulated liquid and vapour flow rates of the vacuum and of the atmospheric columns are shown in Figs 3 and 4

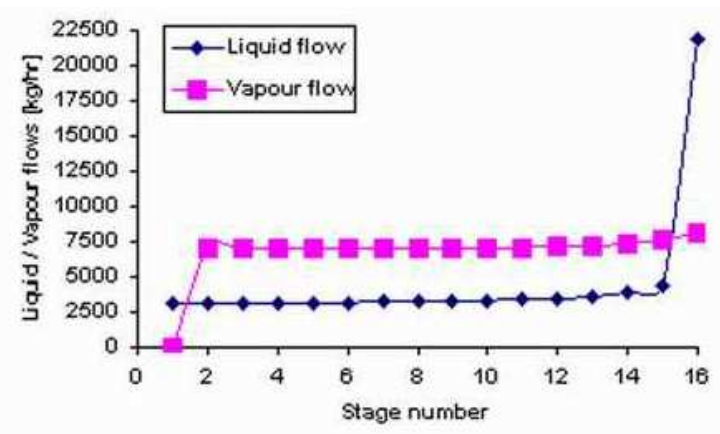

Fig. 3. Internal vapour and liquid flows in the vacuum column (column I)

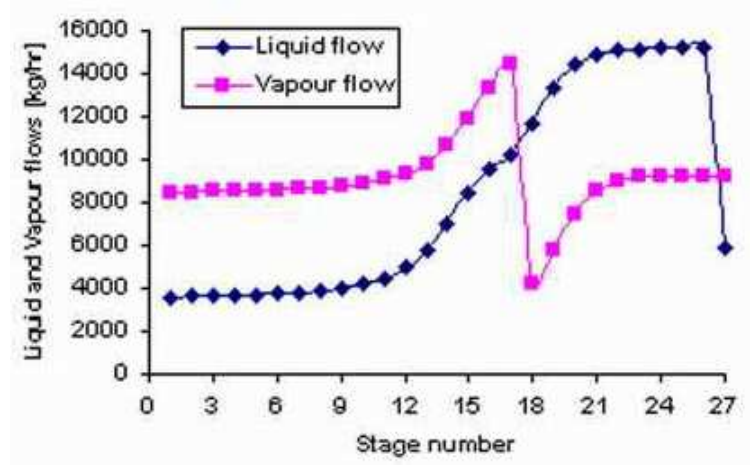

Fig. 4. Internal vapour and liquid flows in the atmospheric column (column II)

The most important data for column sizing is the vapour flow rate. As Figs. 3 and 4 show, the highest vapour flow rates in both columns occur at the feed stages. These maximum vapour flow rates are to be taken into account when calculating the optimal column diameters or when calculating the performance of a column at a given diameter.

\section{Retrofit Scenarios and Calculations}

There are many conceivable ways in which the capacity of the entire system could be increased from 14 tons/h to 20 tons/h. We have considered the following scenarios:

A. It is not necessary to change the structure of the system. Simply by increasing the feed flow rates of the columns will do; the system will keep its separation efficiency.

B. Replacing the internals/packings of some of the existing columns or installing new high efficiency packings in all of the columns.

C. Addition of the available extra column and installing new high efficiency packings in some/all of the columns.

Scenario A is not a real opportunity. If the problem could have been solved this way, the operators of the plant could already have increased the capacity. Installation of new, high efficiency packings is necessary by all means.

Capacity calculation of the columns has been carried out according to the $F$ factor method [5] using the available HETP-F factor diagrams of the different types of new Sulzer Mellapak packings [11]. The $F$ factor method requires the calculation of 
the maximum vapour flow rate, the maximum vapour density, and the knowledge of the column cross sections. The $F$ factor can be calculated according to Eq. 1 .

$$
F_{\text {factor }}=V_{m}^{*} \sqrt{\rho_{V}}
$$

where $\mathrm{V}_{m}$ is the maximum superficial vapour velocity $[\mathrm{m} / \mathrm{s}]$ and $\rho_{v}$ is the maximum vapour density $\left[\mathrm{kg} / \mathrm{m}^{3}\right]$ in the column. Vapour velocity can be calculated using Eq. 2 .

$$
V_{m}=\frac{\dot{M}_{\max }}{\rho_{\mathrm{V}}^{*} A^{*} 3600}
$$

where $\dot{M}_{\text {max }}$ is the maximum vapour flow rate $[\mathrm{kg} / \mathrm{h}]$ and A is the cross-sectional area of the distillation column $\left[\mathrm{m}^{2}\right]$.

In our case, the cross sectional areas of the columns are given. Maximum vapour flow rates and vapour densities are calculated using the process simulation program (Figs. 3 and 4 ). In the following, detailed calculations of the individual distillation columns are shown.

\section{Existing Vacuum Columns}

These are columns Ia and Ib that are operated at $200 \mathrm{mmHg}$ pressure. Parameters required for the $F$ factor calculation in case of 14 tons/h feed flow rate are the following:

Maximum vapour flow rate: $\dot{M}_{\max }=8150.6 \mathrm{~kg} / \mathrm{h}$ (as shown in Fig. 3)

$$
\text { Maximum vapour density: } \rho_{v}=0.1982 \mathrm{~kg} / \mathrm{m}^{3}
$$

Using the parameters of columns $\mathrm{Ia}, \mathrm{Ib}$ the value of the $\mathrm{F}$ factor can be calculated for the increased capacity (20 tons $/ \mathrm{h}$ ). The summed cross sectional area of the two columns is $2.32 \mathrm{~m}^{2}$. The maximum vapour flow rate shown in Fig. 3 is to be multiplied by $1.42857(20 / 14$ tons/h). Using Eqs 1 and 2 the value of the $F$ factor results in 3.13 , this is multiplied by a safety factor of 1.2. Applying a safety factor is usual; in our case it allows $20 \%$ positive deviation from the planned feed flow rate. Accordingly, the final value of the $F$ factor is 3.756. Fig. 5 shows the HETP-F factor function measured out for the Sulzer Mellapak 250.Y, and Mellapak Plus 252.Y packings. These packings are the latest products of Sulzer Chemtech.

As Fig. 5] shows, the separation efficiency of Sulzer Mellapak 250.Y packings is falling at $F$ factor values greater than 2.5 and the separation efficiency of Sulzer Mellapak Plus 252 Y starts to fail at $3.5 \mathrm{~F}$ factor value. It is proven this way that at the increased capacity (20 tons/h; $F=3.756$ ) the vacuum columns could not satisfy the given purity requirements; capacity increase of the vacuum columns cannot be achieved by installing new high efficiency packings. Retrofit scenarios A and B do not work, addition of the available extra column is necessary.

\section{Extra Column Connected Parallel to the Vacuum Columns}

The available extra column (Ic) can be used for increasing the capacity of the vacuum part of the separation system if it is connected parallel to columns Ia and Ib. In this case all the three

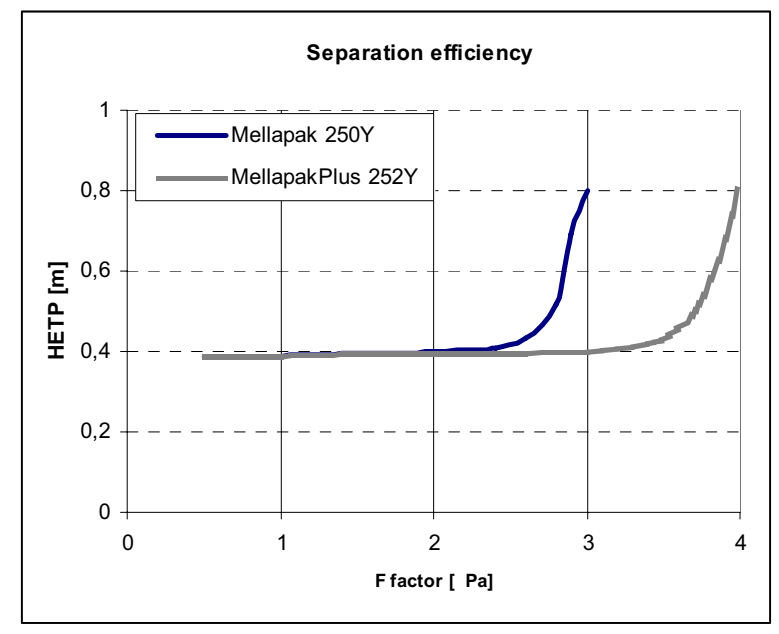

Fig. 5. Separation efficiency of Sulzer packings at $200 \mathrm{mmHg}$

columns are operated at $200 \mathrm{mmHg}$. The diameter of the available column is $1100 \mathrm{~mm}$. The total cross-sectional area that can be reached this way is $3.275 \mathrm{~m}^{2}$ (columns Ia, Ib, Ic together). Using this cross-sectional area and the maximum vapour flow rate, the value of the $F$ factor results in 2.22 for 20 tons/h feed. Using a safety factor of 1.2 again, the final value of the $F$ factor becomes 2.664. Fig. 5 shows that at this $F$ factor value the separation efficiency of the Sulzer Mellapak 250.Y and 252Y packings just begins to deteriorate. Simply just replacing the packings and connecting the available column parallel to the existing vacuum system is not a safe solution, because at increased capacity (20 tons/h) the system would work at its upper capacity limit.

Still, capacity increase can be safely achieved when adding 3 more meters to the packed height of the available extra column (Ic), and when using the Mellapak Plus 252Y structured packing in all the three columns ( $\mathrm{Ia}, \mathrm{Ib}, \mathrm{Ic}$ ). Adding 3 meters to the hull of column Ic can be carried out by the technicians on-site, relatively easily and at moderate cost.

\section{Atmospheric Column}

The atmospheric column is marked column II in Fig. 2. The course of the capacity calculation is similar to the previous calculations.

In case of 14 tons/h capacity, the maximum vapour flow rate in column II is $14442 \mathrm{~kg} / \mathrm{h}$ and the maximum vapour density $\left(\rho_{v}\right)$ is $2.096 \mathrm{~kg} / \mathrm{m}^{3}$. The diameter of column II is $1 \mathrm{~m}$. Using a safety factor of 1.2, the $F$ factor value in column II for 20 tons/h capacity is 1.512 . As Fig. 6 shows, Column II could easily handle the increased capacity when it would be re-filled with Mellapak 250.Y or 252.Y packings.

Since the existing packings of the vacuum columns (Ia, Ib, Ic) are to be replaced by Mellapak 252.Y packings anyway, it is recommended to use the same type of packings in the atmospheric column (column II), too. This way the atmospheric column will work far under its capacity limit, and can equalize the incidental vapour flow upsurges that may occur due to the actions of the process control system. 


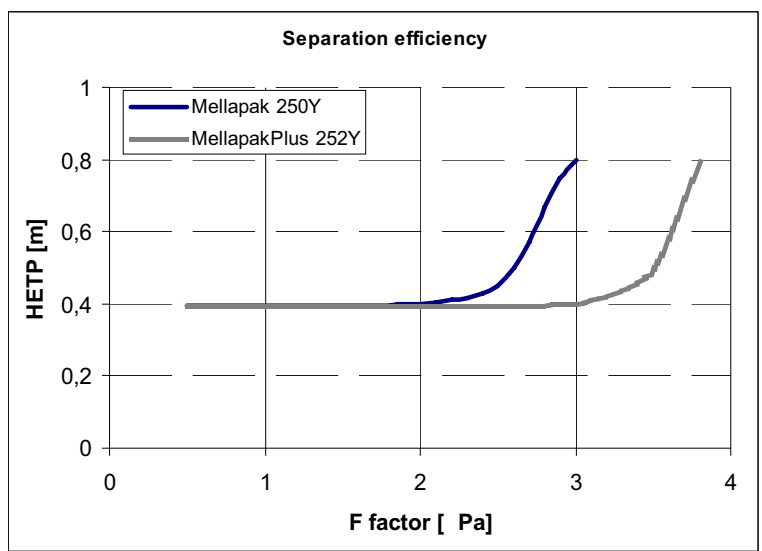

Fig. 6. Separation efficiency of packings at $720 \mathrm{mmHg}$

\section{Suggested Retrofit Design}

Concluding the results of the calculations that have been carried out up to this point it can be stated that increasing of the capacity of the system from 14 tons/h to 20 tons/h is possible, provided that the following process modifications are done:

- The packed height of the available extra column (Ic) is to be elongated by $3 \mathrm{~m}$ and the column is to be connected parallel to the existing two columns ( $\mathrm{Ia}, \mathrm{Ib}$ ) of the vacuum part of the system.

- The internals of all the four columns (Ia, Ib, Ic, II) are to be replaced by 252.Y type of Sulzer Mellapak Plus structured packings.

The suggested retrofit design that can handle the increased 20 tons/h DMF-Water feed is shown in Fig. 7) Discussions with the plant managers made it clear that our suggested retrofit design is the most economical solution that can be found for the capacity increase problem.

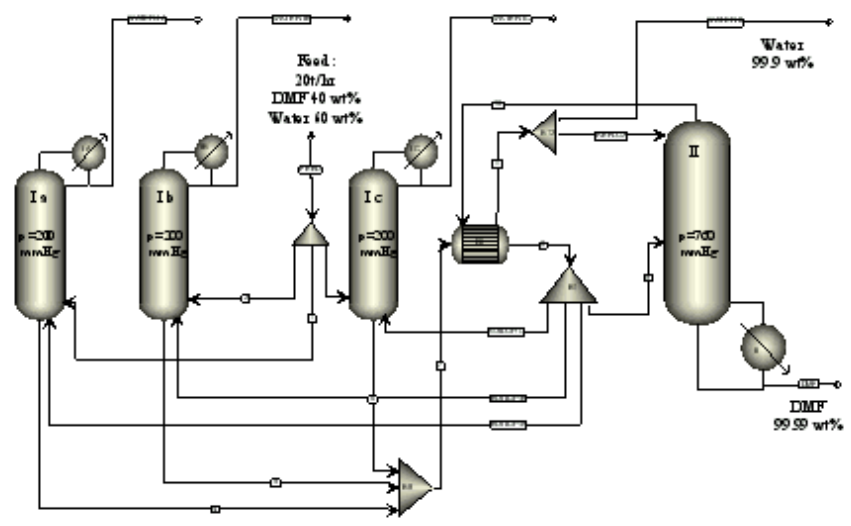

Fig. 7. heat-integrated retrofit design for the separation of 20 tons/h DMFWater mixture

In order to estimate the operating cost of the retrofit structure, energy requirements of the individual distillation columns and the energy requirement of the whole separation system have been calculated. Major results are shown in line 3 of Table 4 Line 2 shows the energy requirement of the present heat integrated lower capacity system. For the sake of comparison, line
1 shows the energy requirement of the lower capacity system, supposing that there is no heat integration. As Table 4 shows, energy integration results in big energy savings. The increasedcapacity energy integrated separation system consumes about half of the energy that would be required for the operation of the non-energy-integrated system at lower capacity.

Tab. 4. Energy requirement for the recovery of DMF

\begin{tabular}{lcccc}
\hline $\begin{array}{l}\text { Distillation } \\
\text { sequence }\end{array}$ & $\begin{array}{c}\text { Feed flow } \\
\text { rate } \\
{[\text { tons } / \mathrm{h}]}\end{array}$ & $\begin{array}{c}\text { Heat duty } \\
\text { of condensers } \\
{[\mathrm{kW}]}\end{array}$ & $\begin{array}{c}\text { Heat duty } \\
\text { of reboilers } \\
{[\mathrm{kW}]}\end{array}$ & $\begin{array}{c}\text { Total heat duty } \\
{[\mathrm{kW}]}\end{array}$ \\
\hline $\begin{array}{l}2+1 \text { columns without } \\
\text { heat integration }\end{array}$ & 14 & 9129.2 & 9635.8 & 18765 \\
$\begin{array}{l}2+1 \text { columns with } \\
\text { heat integration } \\
3+1 \text { columns with } \\
\text { heat integration }\end{array}$ & 14 & 5313 & 1392.6 & 6704.6 \\
\hline
\end{tabular}

The results are even more interesting when the heat duties are related to the mass flow rate of the recovered pure DMF solution. Table 5 shows the calculated energy requirements for the recovery of $1 \mathrm{~kg}$ DMF. The reduction of the energy consumption by using energy-integrated system is $64.26 \%$ in case of original capacity (feed: 14 tons/h) and $65.04 \%$ in case of increased capacity (feed: 20 tons/h).

Tab. 5. Energy requirement for the recovery of $1 \mathrm{~kg} \mathrm{DMF}$

\begin{tabular}{lcccc}
\hline $\begin{array}{l}\text { Distillation } \\
\text { sequence }\end{array}$ & $\begin{array}{r}\text { Feed } \\
{[\text { tons/h] }}\end{array}$ & $\begin{array}{c}\text { Condensers } \\
\text { heat duty[kW] }\end{array}$ & $\begin{array}{c}\text { Reboilers heat } \\
\text { duty[kW] }\end{array}$ & $\begin{array}{c}\text { Total heat duty } \\
{[\mathrm{kW}]}\end{array}$ \\
\hline $\begin{array}{l}2+1 \text { columns without } \\
\text { heat integration }\end{array}$ & 14 & 0.65208 & 0.68827 & 1.34035 \\
$\begin{array}{l}2+1 \text { columns with } \\
\text { heat integration }\end{array}$ & 14 & 0.3795 & 0.0995 & 0.4789 \\
$\begin{array}{l}3+1 \text { columns with } \\
\text { heat integration }\end{array}$ & 20 & 0.3722 & 0.0962 & 0.4685 \\
\hline
\end{tabular}

Comparing the values of the last column of Table 5 clearly shows that the heat-integrated distillation system obtained by our retrofit design has the lowest specific energy consumption.

\section{Conclusions}

It can be concluded that increasing the capacity of the heatintegrated separation system from 14 tons/h to 20 tons/h is possible. The extra column that is available on-site is to be elongated by $3 \mathrm{~m}$, and is to be connected parallel to the existing two columns of the vacuum part of the separation system. The internals of all the columns are to be replaced by new, high efficiency Sulzer Mellapak Plus 252.Y structured packings. Energy requirements of the recovery of $1 \mathrm{~kg}$ DMF have been calculated for both the existing and the suggested retrofit structure. Our results show that the heat-integrated distillation system obtained by our retrofit design has somewhat lower specific energy consumption compared to the existing heat integrated separation system, while its capacity is increased by $42.8 \%$. 


\section{References}

1 Annakou O, Mizsey P, Rigorous Comparative Study of Energy-Integrated Distillation Schemes, Ind. Eng. Chem. Res. 35 (1996), 1877-1885.

2 Bek-Pedersen E, Gani R., Design and Synthesis of Distillation Systems Using a Driving-force-based Approach, Chem. Eng. Proc. 43 (2004), 251262.

3 Chen JC, Harrison IR, Modification of Polyacrylonitrile (PAN) Carbon Fiber Precursor Via Post-spinning Plasticization and Stretching in Dimethylformamide (DMF), Carbon 40 (2002), 25-45.

4 Engelien HK, Skogestad S, Multi-effect Distillation Applied to an Industrial Case Study, Chem. Eng. Proc. 44 (2005), 819-826.

5 Fonyó Z, Fábry G, Vegyipari Múvelettani Alalpismeretek, 2, in Hungarian, Nemzeti Tankönyvkiadó, Budapest, 2004.

6 Kister HZ, Distillation Design, 1st ed., McGraw-Hill Inc., 1992.

7 Mizsey P, Hau NT, Benko N, Kalmar I, Fonyó Z, Process Control for Energy Integrated Distillation Schemes, Comp. Chem. Eng. 22 (1998), 427434.
8 Peters MS, Timmerhaus KD, Plant Design and Economics for Chemical Engineers, 4th ed., McGraw-Hill Intern. Ed., 1991.

9 Pollock GS, Eldridge RB, Neural Network Modeling of Structured Packing Height Equivalent to a Theoretical Plate, Ind. Eng. Chem. Res. 39 (2000), 1520-1525.

10 Rév E, Emtir M, Szitkai Z, Mizsey P, Fonyó Z, Energy Savings of Integrated and Coupled Distillation Systems, Comp. Chem. Eng. 25 (2001), 119-140.

11 SULZER CHEMTECH. Structured Packings for Distillation and Absorption, catalog.

12 Uerdingen E, Fischer U, Gani R, Hungerbühler K, A New Retrofit Design Methodology for Identifying, Developing, and Evaluating: Retrofit Projects for Cost-Efficiency Improvements in Continuous Chemical Processes, Ind. Eng. Chem. Res. 44 (2005), 1842-1853. 